\title{
Dinámicas inmobiliarias y cambios en la morfología urbana del Gran Concepción
}

José Prada-Trigo. Universidad de Concepción, Concepción, Chile.

Natalia Aravena. Pontificia Universidad Católica de Chile, Santiago, Chile.

Pablo Barra-Vieira. Universidad de Concepción, Concepción, Chile.

RESUMEN | El peso del sector inmobiliario en la economía y el crecimiento urbano es un tema que ha atraído crecientemente la atención de los investigadores. Sin embargo, la mayoría de trabajos provienen de Europa, Estados Unidos y, recientemente, de las principales ciudades latinoamericanas. Este artículo contribuye a cubrir la ausencia de estudios sobre la red de ciudades secundarias de esta última región. Con tal fin, desarrolla un análisis e interpretación de las dinámicas de crecimiento urbano en el Área Metropolitana de Concepción (AMC) en Chile, contextualizándolas entre procesos generales y especificidades locales a partir del estudio de sus procesos, mecanismos y morfologías. Se utiliza para ello una metodología cuantitativa-cualitativa que recurre al análisis espacial y entrevistas en profundidad.

PALABRAS ClAVE | áreas metropolitanas, crecimiento urbano, renovación urbana.

ABSTRACT | The importance of the real estate sector in the economy and urban growth is a topic that has increasingly attracted the attention of researchers. However, most of the research comes from Europe, the United States and, recently, the main Latin American cities. This manuscript contributes to covering the absence of studies on the network of secondary cities in this region through an analysis and interpretation of the dynamics of urban growth in the Metropolitan Area of Concepcion in Chile. This work contributes by contextualizing the dynamics between general processes and local specificities through the study of the mechanism, processes and morphologies that explain them. The research uses a quantitative-qualitative methodology through spatial analysis and in-depth interviews.

KEYwORDs | metropolitan areas, urban growth, urban renewal. 


\section{Introducción}

En la actualidad, las dinámicas inmobiliarias no son solamente el motor de crecimiento físico de la mayoría de ciudades, sino también una importante actividad económica, tanto por la edificación de nuevos espacios como por las transacciones financieras que a menudo las acompańan. Esto ha llevado a acuñar conceptos como ciudades del capital, que hacen referencia a la creación y reconfiguración de espacios urbanos a partir de las dinámicas del mercado (Harvey, 2001; Rolnik, 2013). Aunque estos procesos se han estudiado en Europa, Norteamérica y las principales urbes de América Latina, aún no ha habido una reflexión suficiente sobre las dinámicas y configuraciones espaciales del sector inmobiliario en ciudades de la red secundaria de Latinoamérica. El objetivo de este trabajo es analizar e interpretar el modelo de crecimiento inmobiliario en el Área Metropolitana de Concepción (AMC), conectándolo con la literatura internacional a través del estudio de sus procesos, mecanismos y morfologías. Entre estos aparecerían, además de fenómenos globales, otros elementos locales que escaparían de las lógicas de reproducción del espacio: el peso de las universidades como vectores de operaciones inmobiliarias destinadas a captar las demandas de alojamiento de los estudiantes en sus alrededores; la importancia de atractivos paisajísticos locales, como la costanera del río Biobío, que habrían configurado áreas de prestigio a pesar de su deficiente conectividad; o la incidencia de fenómenos catastróficos (terremoto del 27 de febrero de 2010 en Chile, conocido como 27-F). De igual forma, en el contexto local existiría una notable influencia de las empresas inmobiliarias en la proyección de crecimiento de la ciudad y su respectiva configuración, que estarían marcando las dinámicas urbanas. Así, este artículo vendría a cubrir un aspecto, el modelo de crecimiento urbano en ciudades secundarias, con poca literatura en Latinoamérica, quedando fuera de su foco el rol de los actores públicos locales y el marco regulador, a pesar de que también se refiera a estos a la hora de analizar e interpretar el dinamismo urbano, que se enfoca en los agentes privados. La selección del caso de estudio se justifica también porque esta es la segunda mayor área metropolitana de Chile y un espacio de gran crecimiento inmobiliario.

La metodología que se emplea es mixta, con utilización tanto de fuentes estadísticas como de entrevistas, lo cual permite triangular la información. En el caso de los datos, provenientes del Instituto Nacional de Estadísticas (INE) y la Cámara Chilena de la Construcción (cchc), se los ha representado o trabajado mediante análisis espacial, lo que permite obtener resultados más complejos e incluso determinar futuras áreas de crecimiento. Los datos estadísticos se han enriquecido con la realización de 21 entrevistas en profundidad a actores clave, lo que matiza, refuerza o complementa la información estadística. A continuación, tras una revisión de la literatura, que pone su énfasis en dinámicas generales y en procesos propios de Latinoamérica, se introducen la metodología y la dinámica inmobiliaria en Concepción. Posteriormente se lleva a cabo el análisis del caso de estudio, a partir de tres aspectos: verticalización del centro urbano, expansión de la ciudad en la periferia, y mecanismos de puesta en valor de nuevas áreas para el crecimiento urbano. 


\section{Revisión de la literatura: crecimiento urbano y mercado inmobiliario}

Una de las primeras reflexiones sobre el rol en la economía y el crecimiento urbano del sector inmobiliario es la de Henri Lefebvre (1970) en torno al concepto de "circuito secundario de acumulación". Con dicha noción Lefebvre hacía referencia a una reinversión de los excedentes del capital productivo en el sector inmobiliario para contrapesar la caída de la rentabilidad del mismo en ciertos periodos. La crisis económica de 1973 en Chile supuso una creciente transferencia directa de capital (no solamente de excedentes) hacia el circuito secundario, permitiendo generar importantes beneficios vinculados al sector inmobiliario. En consecuencia, su incidencia sobre el PIB, empleo, inversión y gasto resultaría en la actualidad estratégica (Daher, 2013). Dicho circuito, además, contribuiría a fijar el capital en el espacio (De Mattos, 2016; Harvey, 2001), dado que, como señalan Lois et al. (2016), el capital invertido es inmóvil, es decir, no puede reubicarse sin ser destruido, lo cual implica la creación de un paisaje físico con fines de producción, circulación, intercambio y consumo. Con esta dinámica, las propias ciudades se transformarían en mecanismos para la absorción y reproducción de capital, integradas en el circuito de acumulación (Christophers, 2011).

En ese contexto, las inversiones inmobiliarias tendrían un peso creciente en la profunda metamorfosis urbana que se vive hoy (Inzulza-Contardo, 2016). Un aspecto esencial de este fenómeno lo constituye la función estratégica del mercado hipotecario, ejercida mediante la expansión de los créditos para la compra de vivienda (Méndez, 2018), sean privados, vía instituciones bancarias y de crédito, o públicos, a través de la concesión de subsidios para la adquisición de vivienda en el mercado o de exenciones fiscales (Hidalgo et al., 2017). Este ha sido un fenómeno global, que se ha expandido a partir de la inclusión de las clases medias y bajas al circuito financiero, con la intención de convertirlas en propietarias (Rolnik, 2013). La abundancia en la concesión de créditos actúa como un incentivo a la demanda, dinamizando el mercado inmobiliario y a menudo convirtiendo las viviendas en un activo financiero en el cual invertir, con el que obtener hipotecas o generar un beneficio mediante su arriendo o futura venta (Aalbers, 2016; Rolnik, 2013). La mayoría de las inversiones se han dirigido hacia los nichos de mayor rentabilidad, a escala interurbana o intraurbana. En este último caso, algunos sectores de la ciudad -espacios centrales, zonas residenciales de mayor calidad en la periferia, renovaciones del centro, costaneras- pasarían a atraer con más fuerza a los inversores, en un proceso que se ha expandido desde los países anglosajones hacia el sur de Europa y Latinoamérica (Borsdorf \& Hidalgo, 2007; Janoschka \& Sequera, 2016).

El cambio del rol del Estado, que habría pasado desde una gestión del crecimiento urbano hasta un apoyo a los desarrollos promovidos desde el sector privado (Brites, 2017; Molina et al., 2019; van Lindert, 2016), es fundamental en este cambio, al crear un clima óptimo para garantizar no solo mayor fluidez al capital, sino también mayor libertad de acción al mismo. Se pone así en crisis la relación previa entre las esferas de lo público y de lo privado, permitiendo un mayor espacio de actuación al capital inmobiliario y financiero (Ciccolella, 2016). El resultado, en un contexto de atonía del sector público, es que los agentes privados tenderían a desmontar las 
ciudades en fragmentos urbanos, con una lógica cada vez más selectiva y acelerada (Ciccolella, 2016; Janoschka \& Sequera, 2016). Mediante mecanismos como la adquisición de terrenos, el sector privado pasaría a generar paisajes urbanos altamente diferenciados, discontinuos y complejos, relacionados en las áreas periurbanas con condominios y viviendas sociales; y en los centros urbanos, con operaciones de renovación urbana, generalmente de menor escala y más dispersas, pero igualmente de gran impacto, pese a su menor visibilidad en comparación con los desarrollos suburbanos (Steel et al., 2017). En este marco, no puede obviarse la conexión que existe entre el tipo de institución predominante (no solo pública, también de elites económicas) y formas del crecimiento urbano; así, los intereses vinculados al suelo interactuarían con las instituciones formales, determinando el uso de recursos y la generación de políticas (Steel et al., 2017; Storper, 2013).

En América Latina, según Vergara-Arribas (2020), existe un déficit en la investigación sobre el sector inmobiliario, sus lógicas, mecanismos y discursos en la producción del espacio, a pesar de su relevancia creciente y su influencia en la reproducción de desigualdades espaciales y en la estratificación social. En un trabajo pionero en la región sobre fondos de inversión inmobiliaria, Daher (2013) verificó su fuerte tendencia concentradora en lo sectorial y territorial, y su sesgo metropolitano y hacia las comunas de mayores ingresos, identificando los espacios donde residen los sectores de mayor renta y donde el precio del suelo es más elevado, como aquellos a los que se dirige el mayor volumen de inversiones. Por el contrario, las áreas de residencia de los sectores más pobres y con menor demanda solvente recibirían menos inversiones (De Mattos, 2016; López-Morales, 2015), algo que Michelini y Pintos (2016) identificaron también para un caso argentino. Así, en Latinoamérica la ciudad se puede entender también como parte central de los procesos de acumulación capitalista, reproduciendo lógicas que se manifiestan en la morfología y patrones residenciales (Dammert et al., 2019). En este sentido, como señalan Hidalgo, Santana \& Link (2018), la liberalización de los mercados urbanos llevó a que el precio del suelo pasara a condicionar el acceso de la población más pobre a la vivienda, dando lugar a su segregación hacia la periferia. El trabajo de De Mattos et al. (2016) también indica una fuerte selectividad geográfica en las inversiones inmobiliarias, no solamente en lo espacial, sino también en el producto (departamentos o viviendas), algo que se verifica en el estudio de caso.

La concreción espacial y morfológica de este fenómeno sería asimilable a algunos conceptos que hacen hincapié en las especificidades de América Latina y en las dificultades que existen a la hora de traspasar conceptos formulados en otras latitudes (Molina et al., 2019). Algunos de los aportes más significativos en este sentido son los de Ciccolella (2016) o Abramo (2012). El primero hace referencia a la ciudad latinoamericana como mestiza, en tanto resultado de la superposición de distintos modelos (agroexportador, desarrollista y neoliberal), lo que se reflejaría tanto en el agravamiento de las desigualdades sociales, económicas y territoriales gestadas en los años noventa, como en la fragmentación a causa de la creciente selectividad territorial de las inversiones inmobiliarias y productivas. El resultado sería un modelo altamente desigual, similar al referido anteriormente (Borsdorf \& Hidalgo, 2007; 
Janoschka \& Sequera, 2016), pero que incorporaría la herencia de los modelos anteriores y la idiosincrasia de las ciudades de la región (Ciccolella, 2016).

El segundo enfoque que hace referencia a especificidades de América Latina remite a la existencia de una ciudad com-fusa (Abramo, 2012; Cattaneo, 2011; Lencioni, 2014). La misma estaría condicionada por dos fuerzas de alcance complementario: por una parte, el impulso neoliberal vinculado al empresarialismo urbano y las políticas públicas enfocadas hacia la mencionada propietarización de sectores amplios de la población (Hidalgo et al., 2017); y por otra, el fuerte incremento de la movilidad y la conectividad. Dicho fenómeno -el que denominan ciudad comfusa-vendría a complejizar un proceso de intenso crecimiento hacia la periferia que ha sido identificado por varios autores (Dammert et al., 2019; Hidalgo, Santana \& Link, 2018; López-Morales, 2015), fuertemente segregador y privatizador, pero que se desarrollaría en paralelo a una verticalización de los centros, buscando aumentar las plusvalías también en estas áreas urbanas, algo que Fedele y Martínez (2015) analizaron para el caso de Santa Fe (Argentina) y recientemente Fuentes y Pezoa (2017) para el Área Metropolitana de Valparaíso. De esta forma, las ciudades se contraen o compactan en las áreas centrales o bordes fluviales revalorizados, expandiéndose en paralelo hacia nuevas periferias donde la combinación de suelo disponible y barato orienta la construcción de viviendas sociales, quedando este proceso bajo la lógica del mercado (Brites, 2017).

En este sentido, Chile es un laboratorio excelente para analizar los cambios en el crecimiento de las ciudades vinculados a la liberalización del mercado de suelo, algo que viene ocurriendo desde la década de los setenta en un proceso por el cual constructoras, promotores o corredores de bienes raíces sustituyen al Estado como referente en el campo de la vivienda (López-Morales, 2016). Junto con esto, las reformas en el mercado de capitales permitieron nuevas maneras de acceder a liquidez y financiamiento, generándose el primer acople entre sector financiero y promoción urbana (Arenas \& Mesa, 2006), lo que aceleró el crecimiento de las ciudades, impulsado por los cambios en los planes reguladores y la extensión de los subsidios estatales hasta las clases medias (Fuentes et al., 2017). Así, el actual modelo de vivienda social en Chile tiene su origen a finales de la década de los setenta, cuando se impulsó el sistema de subsidio habitacional (Hidalgo, 1999). El mismo, bajo la justificación de disminuir el déficit existente, creó y consolidó un sistema subsidiario y tercerizado al mundo privado a través de la entrega de vouchers transables en el mercado por una vivienda propia (Fuster-Farfán, 2019). Sin embargo, dejar la iniciativa al mercado, con la dificultad que esto implica para construir viviendas sociales en terrenos de alta plusvalía y con cierta centralidad, ha provocado que la planificación del espacio sea en función de la rentabilidad del suelo (Hidalgo et al., 2017). El resultado es un modelo segregado, en el que la vivienda subsidiada se localiza en las áreas periféricas de menor valor.

No obstante el carácter general de tales procesos, la mayoría de estudios se han desarrollado en referencia a Santiago (Cattaneo, 2011; De Mattos et al., 2016; Lukas \& López-Morales, 2017). Existen, sin embargo, algunos trabajos recientes -aunque incipientes- que se interesan por otros sistemas metropolitanos de Chile, refiriéndose, por ejemplo, a una dispersión selectiva de los servicios hacia la periferia 
(Napadensky \& Orellana, 2019) o a las dinámicas recientes en el Gran Valparaíso (Fuentes \& Pezoa, 2017). Pese a que Pérez et al. (2019) han estudiado el proceso de verticalización en un barrio determinado de Concepción, lo han hecho sin abarcar las dinámicas del conjunto del Área Metropolitana. Aun así, estos trabajos anuncian ya algunas diferencias morfológicas y funcionales entre el Área Metropolitana de Santiago y otras secundarias. Por esto, la posibilidad de analizar los procesos en espacios de menor tamańo, pero con un importante dinamismo inmobiliario, es una oportunidad de aproximarse a los vínculos existentes entre transformación económica y fabricación de espacios urbanos en otras escalas (Cattaneo, 2011).

\section{Metodología y área de estudio}

Este artículo se realizó utilizando una metodología mixta, compuesta por datos cuantitativos y entrevistas a actores clave, con el fin de visualizar e interpretar las dinámicas inmobiliarias en el AMC y cómo ellas han configurado su morfología urbana. Como primer paso, se llevó a cabo una revisión de trabajos sobre esta temática y sus componentes, a nivel nacional e internacional. La mayoría de esos estudios se habrían desarrollado en ciudades europeas y norteamericanas, siendo incipientes en América Latina, por lo que se hizo hincapié en aquellos aportes referidos al ámbito regional. Posteriormente, se identificó y entrevistó a actores clave en el crecimiento inmobiliario del AMC, principalmente corredores de propiedades y empresas inmobiliarias. A estos se añadió un representante de la Cámara Chilena de la Construcción (cchc), encargado de estudios a nivel zonal de esta asociación gremial. Para complementar la información y abarcar un espectro lo más amplio posible, se incluyó a tres representantes del sector público, uno a nivel regional y dos pertenecientes a las comunas donde se había manifestado mayor dinamismo (Concepción y San Pedro de la Paz). En total, se llevaron a cabo 21 entrevistas, primero con los actores localizados inicialmente y luego aplicando el método de "bola de nieve" para contactar con otros no detectados previamente. Esto se realizó hasta encontrar un "punto de saturación" en la información, cuando esta se volvía redundante. Con la finalidad de favorecer la expresión de las opiniones con libertad, se decidió recurrir al anonimato en el momento de transcribir alguna parte de las entrevistas en el artículo, otorgando un código a cada uno de los entrevistados para su uso en este trabajo (sigla ACT seguida de un número identificatorio).

A continuación, se procedió a la búsqueda de datos cuantitativos que pudieran complementar esta información, tratando de delimitar las dinámicas de crecimiento horizontal y vertical en el AMC y su escenario de desarrollo futuro. Para ello se utilizó tanto información espacial directamente disponible como otra de más difícil acceso, que hubo que requerir mediante la Ley de Transparencia, como el uso de suelo en el Plan Regulador Metropolitano, las áreas de expansión urbana o la densidad de viviendas. La información recibida se editó y trabajó a escala de manzana censal, en unos casos a través de técnicas descriptivas y en otros mediante un análisis de autocorrelación espacial, utilizando el software ArcMap 10.5 para aplicar el índice I de Local Moran. Este se aplica agrupando valores similares de un indicador en unidades espaciales homogéneas (clústeres) donde se concentran espacialmente los 
valores más altos o más bajos de dicho indicador. Este análisis tiene la ventaja de que resulta fácil de implementar y visualizar, especialmente en trabajos exploratorios de datos espaciales, a pesar de que establecer comparaciones entre casos puede ser complejo, debido a la variabilidad de las fuentes (Anselin, 1995).

El AMC, 500 kilómetros al sur de Santiago, ha experimentado un fuerte crecimiento inmobiliario en los últimos ańos, observándose un aumento de la oferta habitacional en diversas comunas, principalmente en Concepción, San Pedro de la Paz y Chiguayante (Forcael et al., 2013), oferta que ha sido uno de los motores económicos del área metropolitana (Prada-Trigo, 2019a). En este sentido, la edificación autorizada habría sufrido un incremento notable durante el siglo XXI, pasándose de unas 8.000 viviendas por año durante la segunda mitad de los años noventa a unas 12.000, pese a momentos puntuales de estancamiento (INE, 2018). El terremoto de 2010, de una magnitud de 8,8 en la escala Richter, contribuyó a dinamizar este sector y a espolear la demanda de vivienda. De esta forma, en los últimos años, el AMC ha experimentado un crecimiento vertical en su centro y horizontal en sus comunas periféricas, producto del aumento de la inversión inmobiliaria, según indican Forcael et al. (2013). Esta imagen es paralela a una dinámica en la cual, desde 2013, la oferta de casas, hasta ese momento mayoritaria, disminuye en favor de los departamentos, síntoma del mencionado proceso de verticalización en el AMC. Según la cchc (2018), durante la segundad mitad de 2018 se comercializaron 2.630 proyectos en el Gran Concepción (1.857 departamentos y 773 casas). A nivel metropolitano, la mayor venta de departamentos se observó en Concepción, con un 67\% del total, seguido de San Pedro, con un 21\%. En cuanto al mercado de casas, San Pedro es la comuna con más transacciones (43\%), seguida de Concepción, con el 32\% (Prada-Trigo, 2019a). A partir de este panorama general, a continuación se desarrolla un estudio con mayor detalle de las dinámicas y causas de la verticalización, suburbanización y las futuras áreas de expansión urbana, lo que contribuye a develar matices de interés en relación con los tópicos destacados en la revisión de la literatura.

\section{Verticalización: del centro a los nuevos espacios de rentabilidad}

Desde la aparición de los primeros edificios en altura, a inicios del siglo pasado, se ha dado una progresiva proliferación de estas estructuras, que son hoy un rasgo distintivo de las ciudades. En el caso del AMC, en su centro es posible encontrar un número creciente de tales construcciones (Pérez et al., 2019), producto del boom inmobiliario de la última década, pero que coexiste con áreas de baja altura. El cambio que ha experimentado recientemente el mercado inmobiliario es significativo, ya que se observa un aumento de las edificaciones en altura, que responde a que este tipo de proyectos se ha ido normalizando con el tiempo, además de que cada vez más clientes -como lo son los profesionales jóvenes que cuentan con buen nivel de ingreso, o las parejas sin hijos- están optando por vivir en departamentos, por la cercanía al centro y seguridad. Otro factor es el precio del suelo, que ha ido en aumento, por lo que en la actualidad los proyectos de densificación se construyen en su mayoría cerca del centro urbano (Cares et al., 2017; Schovelin, 
2004). Este dinamismo se debe, además, a ciertos rasgos propios, como el carácter central de Concepción en el centro-sur del país, su peso económico, dinamismo comercial o identidad como ciudad universitaria, lo que genera una alta presencia de estudiantes, que son vistos como un nicho de potenciales clientes para compra o arriendo de departamentos (Prada-Trigo, 2019b).

A través de un análisis inicial, en la Figura 1 (izquierda), se pueden apreciar los permisos de edificación desde 2010 a 2017 en el centro de Concepción, según el número de pisos, lo que permite visualizar el crecimiento vertical en la presente década, intensificado a lo largo de ejes como las avenidas Paicaví y Los Carrera, o en sectores como Collao, en las cercanías de las universidades. Además, en la cartografía se incluye la densidad de vivienda, que comienza a mostrar áreas con más intensidad, marcando los sectores de mayor renovación urbana. Los mismos, aunque no resultan tan notorios en cuanto a superficie como las operaciones en la periferia, estarían generando un fuerte impacto en el centro de la comuna, en concordancia con lo mencionado por la literatura internacional (Steel et al., 2017). El mecanismo más común para la construcción en altura en el centro ha sido la compra, por parte de constructoras, de varios terrenos adyacentes, pertenecientes generalmente a particulares, para consolidar un solar de mayores dimensiones donde levantar el nuevo edificio (DemoData, 2018).

Figura I | Permisos de edificación en el centro de Concepción (2010-2017), según número de pisos (izquierda) y situación del caso de estudio (derecha)

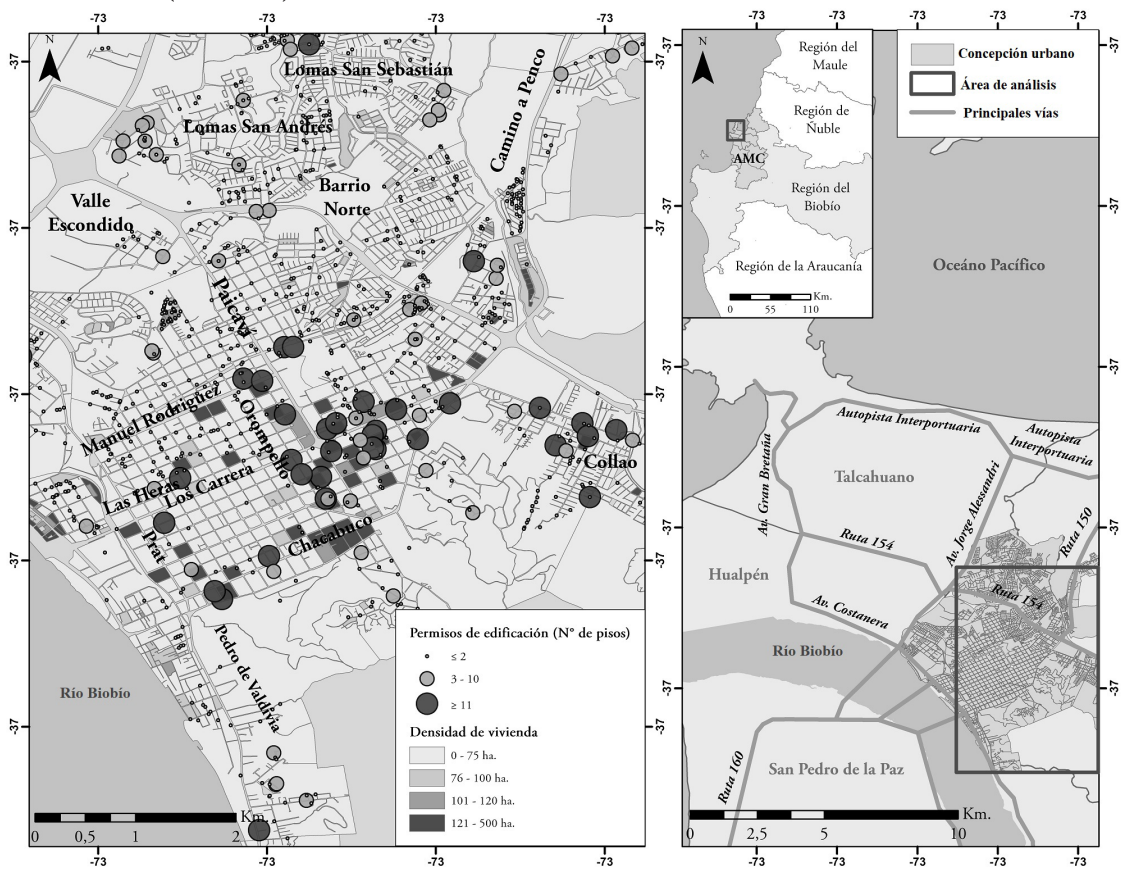

FUENTE: ELABORACIÓN PROPIA A PARTIR DE INE (2OI7) 
La aplicación de un análisis de autocorrelación espacial (Figura 2) ratifica esta primera impresión de renovación en altura concentrada en algunos sectores del centro. En esta zona, áreas como Collao manifiestan un crecimiento vertical incipiente, con la Universidad del Bío-Bío (uBB) como "palanca” del mismo. Otras zonas periféricas, como Valle Escondido, Valle de Nonguén o avenida 21 de Mayo (corredor urbano donde se ha renovado la avenida principal), muestran una dinámica similar. En especial, destaca Pedro de Valdivia Alto, espacio ubicado en el lado norte de la costanera del Biobío y que aparece como un área de prestigio, en parte por sus valores paisajísticos, asociados a la costanera, como sucede en otros casos nacionales e internacionales (Brites, 2017; Hidalgo, Rodríguez \& Alvarado, 2018). Todos ellos se han visto recientemente sometidos a los mencionados procesos de verticalización.

Más allá de Concepción, en la comuna de San Pedro de la Paz también se ha producido un fuerte proceso de verticalización, con un aumento de departamentos que, pasando de 2.496 en 2002 a 8.529 en 2017, habría supuesto el noveno mayor incremento a nivel nacional en ese período (Diario Concepción, 2019). El análisis mediante autocorrelación espacial (Figura 2) permite observar que, en esta comuna, el crecimiento en altura se concentra en los sectores de Andalué, Camino a Santa Juana y Huertos Familiares, donde se está intensificando la aprobación de permisos para viviendas con un gran número de pisos. Esto contrasta con el resto de la comuna, donde no existiría esa concentración de edificios en altura, lo que hace de este un fenómeno muy polarizado. Veríamos, por lo tanto, una renovación muy fragmentada y concentrada en zonas de prestigio, de manera similar a lo que refiere la literatura nacional e internacional (De Mattos, 2016; Janoschka \& Sequera, 2016).

En el caso de Concepción, la ausencia de una regulación pública del arriendo estudiantil y de residencias universitarias generaría un nicho de negocio vinculado a la inversión inmobiliaria con fines de arriendo, situación distinta a la de otros países (Prada-Trigo, 2019b). En este sentido, los inversionistas son otro factor al que responde el aumento de edificios en el Gran Concepción, fenómeno muy ligado a los "inversionistas hormiga", personas que aprovechan la relativa facilidad que existe para obtener créditos e invierten en una vivienda para destinarla a arriendo (cchc, 2017). Su fin es mejorar su renta o ahorrar para su vejez con un riesgo relativamente bajo, vinculando inversión y crecimiento urbano en nichos de rentabilidad, de una forma similar a como se manifestaba en la revisión de la literatura (Aalbers, 2016; Rolnik, 2013). A partir de ello, en el trabajo cualitativo se reconoce la importancia tanto de la influencia que tienen la presencia de estudiantes en la ciudad para las construcciones en altura, como las transformaciones inmobiliarias provocadas por los "inversionistas hormiga". En este sentido, Аст1 indicaba: "Hemos detectado en nuestros estudios que el $30 \%$ de la demanda potencial de un proyecto en el centro corresponde a inversionistas hormiga (...) no son grandes tenedores de recursos, no son grandes inversores de muchas cantidades de departamentos, uno o máximo dos. Es gente común y corriente [la que invierte] que, ante la incertidumbre de los fondos de pensión, de cuáles van a ser sus tasas de previsión futura, ven en el mercado inmobiliario una alternativa de refugio, más cuando Concepción tiene un contexto de ser ciudad universitaria, que genera una amplia demanda por ese mercado”. 
FIGURA 2 | Autocorrelación espacial de permisos de edificación (número de pisos) en AMC

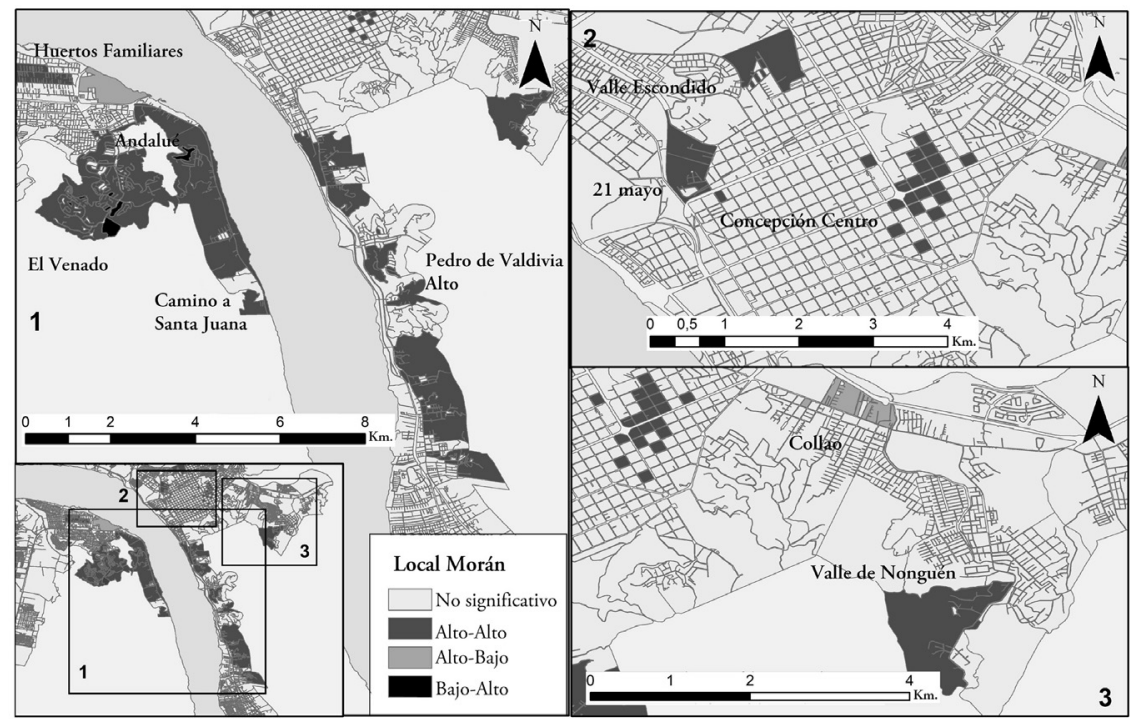

FUENTE: ELABORACIÓN PROPIA A PARTIR DE INE (2OI7)

Es interesante la puntualización del АCT1, que subraya el valor de las inversiones inmobiliarias como forma de fijar y rentabilizar capitales ante la incertidumbre del sistema de pensiones. Esta idea se vincula claramente con lo planteado en la revisión de la literatura sobre la generalización de las hipotecas y aparición de paisajes urbanos, donde el objetivo es obtener beneficios mediante nichos de mercado (Aalbers, 2016). En consecuencia, también aparecerían casos en que, desde otras ciudades, se adquirirían departamentos en el Gran Concepción. Lo mismo ocurre en el contexto de arriendos a estudiantes, que permiten crear esos "espacios del capital". Como afirma ACт7: "Hay mucho inversionista que viene ahora a Concepción, porque tiene ya dos departamentos en Santiago y viene acá, porque cuando tú tienes uno o dos departamentos [lo] empiezas a ver como proyección a futuro, y Concepción [está] lleno de estudiantes".

Como señala otro de los entrevistados [АСт15]: "Mucho universitario genera altura, no casas (...). La gente que nos compra, muchas veces es para arriendos universitarios (...) en general son departamentos que se llaman 'mariposa', que tienen dos dormitorios". Esta relevancia que posee la gran masa de universitarios presentes en la zona también queda reflejada en lo expresado por АСт10: "Concepción es una ciudad universitaria, es un tema importante. Si tú te fijas en las locaciones que tenemos en el sector de la Universidad San Sebastián, tenemos Las Tres Pascualas, Cruz; Ainavillo está a tres cuadras de la Universidad del Desarrollo, cerca de la Universidad del Bío-Bío... El tema universitario tiene que ver mucho con el perfil del inversionista”. 
El fenómeno de densificación urbana en el centro de Concepción se empezó a observar a finales del siglo xx, lo que generó una renovación inmobiliaria de calles como Las Heras, Orompello, Prat y el sector de Las Tres Pascualas (cchc, 2017). El actual Plan Regulador Comunal (PRC) plantea el área central de Concepción como espacio sin limitaciones en altura (algo que en este momento se encuentra en discusión en el proceso de modificación del mismo). Existen manzanas con gran densidad de viviendas, como las localizadas en calle Chacabuco o las cercanas a la avenida Paicaví, que cuentan con varios edificios de departamentos. La densificación para uso predominantemente residencial, sin aparición de nuevos servicios especializados, habría sido la tónica de este fenómeno, según Pérez et al. (2019). Esta idea de renovación urbana, en ocasiones a costa de barrios consolidados con viviendas de una o dos plantas, es algo que señala АСт12 cuando indica: "Нay un tema de la verticalidad del centro: quedan disponibles hoy como siete hectáreas [sin construir] en total para hacer algo; eso es uno o dos años, y después vamos a tener que empezar a echar abajo las casas".

Este dato ratifica la dificultad para encontrar nuevo suelo edificable en el centro, por lo que las operaciones tratan de obtener el máximo provecho y generar plusvalías mediante la edificación de grandes alturas. En esta línea, se recurre a fusionar terrenos para construir proyectos de mayor altura, como señala АCт21: "Para construir con esa altura no sirven los terrenos como están divididos en el centro de Concepción, [donde] la mayoría tiene frente de 10-12 metros; por lo tanto, implica operación de fusión de unos cuatro predios, por lo menos”. Esto también estaría generando la aparición de edificios en altura hacia la periferia, en zonas con atractivos por su cercanía a las universidades o por contar con elementos de valor natural, algo que corrobora ACT15 al seńalar: "Hay un polo que se ha desarrollado cerca de la Universidad del Desarrollo que llega a la 'Plaza de los Dinosaurios' y a Carrera (...), porque tiene buena conectividad para todos lados (...) tiene centro de salud, supermercado, está cerca de universidades, está a un paso de todo y es como el centro de Concepción, pero oriente".

Cabe señalar que el Ministerio de Vivienda y Urbanismo (MINVU) ha incentivado la densificación urbana, creando subsidios a la edificación de proyectos habitacionales, los cuales deben cumplir con ciertos requisitos, como construir un mínimo de 75 viviendas por hectárea, aumentando el monto monetario otorgado al construirse 120 viviendas por hectárea (MINVU, 2011). En este sentido, como señala ACT14: “[El crecimiento vertical] parte generalmente por un tema del valor del terreno; cuando el terreno empieza a ser caro, empieza a subir. La única oportunidad que tiene uno de darle rentabilidad al negocio es haciendo departamentos. La densificación es natural en todas las ciudades de Chile". De esta manera, con la lógica del precio del suelo se inicia un proceso de densificación urbana amparado en las políticas públicas, como se señalaba en la revisión de la literatura. Esto, cuya finalidad es principalmente el arriendo o la inversión, resulta más llamativo si se tiene en cuenta que en el periodo 2002-2017 la población residente en el centro urbano de Concepción (Paicaví, Los Carrera, Víctor Lamas y Prat) pasó de 13.149 a 8.874 habitantes (INE, 2017). En este sentido, АСт21 indicaba: "Es un tipo de producto inmobiliario que está financiado y por eso tiene demanda. No responde a crecimiento demográfico ni a la 
migración de personas (...) son estudiantes o trabajadores que normalmente viven por temporadas (...) está respondiendo a una lógica de mercado y no demográfica”.

\section{Crecimiento horizontal: la tendencia que no para}

Junto con este crecimiento vertical, otras comunas del AMc, como San Pedro, Chiguayante, Penco, Santa Juana o Coronel, experimentan una expansión horizontal, ya que disponen de amplias superficies de suelo para el crecimiento en extensión. Mediante análisis espacial (Figura 3), se revisaron las nuevas construcciones desarrolladas entre 2012 y 2017 en espacios destinados por la planificación territorial a Zonas de Extensión Urbana y que no poseían urbanización anterior, correspondiendo a zonas de baja densidad poblacional. En su mayoría aparecen situadas en ámbitos periféricos, los que -según es posible apreciar- corresponden a las zonas de menor densidad del Amc, como es el caso de Penco, Coronel y Santa Juana. A partir de 2010, y con el reimpulso a la urbanización tanto por los proyectos de reconstrucción posterremoto como por las ayudas gubernamentales o subvenciones a la compra de viviendas, se vive el proceso de desarrollo de nuevas construcciones en las zonas de extensión urbana (Figura 3). Esto se vincula directamente con lo señalado en la revisión de la literatura sobre la regulación de la vivienda subsidiada por parte del mercado y la propietarización de los grupos de ingresos más bajos (Fuster-Farfán, 2019; Hidalgo et al., 2017), a menudo en ámbitos fuertemente segregados.

De acuerdo con cifras del INE (2018), cada año en el AMC se construyen unas 5.000 viviendas, de las cuales el $70 \%$ son edificios. A la larga, esto lleva a que se construyan edificios incluso en la periferia urbana, lo que responde a los subsidios creados mediante los Decretos Supremos 19 y $116 .{ }^{1}$ Como es posible observar en la Figura 4, los proyectos desarrollados en los años 2016 y 2017 con subsidios de integración -es decir, que intentan acercar las personas de menores recursos a las áreas de desarrollo urbano "clase media"- ocupan, sin embargo, espacios asociados más a la periferia que a lugares centrales. Se concentran en las comunas de Coronel, San Pedro y en el sector camino a Penco, generándose así, al igual que en otras ciudades de Latinoamérica, un crecimiento fuertemente segregador para la vivienda subsidiada (Dammert et al., 2019). Tal tendencia explica algunas problemáticas de movilidad asociadas a la Ruta 160 por una expansión periférica del AMC hacia ese sector, propiciada por la disponibilidad de suelo urbano no consolidado y la compra de estos paños por inmobiliarias desde los años setenta, para su posterior venta o desarrollo propio. De esa manera, parte del crecimiento periférico de los últimos años se vincula al desarrollo de proyectos de integración urbana, donde los edificios en áreas como San Pedro de la Costa, Lomas Coloradas y Los Pioneros, han provocado un aumento en la densidad poblacional y, con ello, la necesidad de transporte hacia el centro de Concepción, donde se concentran los servicios. A su vez, estos

1 Decreto I9: Reglamenta Programa de Integración Social y Territorial. Ministerio de Vivienda y Urbanismo. Promulgado en mayo 2016; publicado en julio 2020. En http://bcn.cl/21122 | Decreto 116: Reglamenta Subsidio Habitacional Extraordinario para Proyectos de Integración Social. Ministerio de Vivienda y Urbanismo. Promulgado en diciembre 2015; publicado en febrero 2015; última versión, enero 2018. En http://bcn.cl/2l12f 
subsidios han propiciado el desarrollo de otras áreas que se han mantenido como ideales para la expansión urbana por parte de los instrumentos de planificación, dada su conectividad y cercanía al centro del Amc. Tal es el caso de Hualqui, donde se han desarrollado proyectos de integración, expandiendo con ello el límite urbano de la ciudad y generando barrios nuevos, cuyo crecimiento consolida aún más su papel como parte del AMC.

FIGURA 3 | Nuevas construcciones en Zonas de Extensión Urbana del AMC (2012-2017)

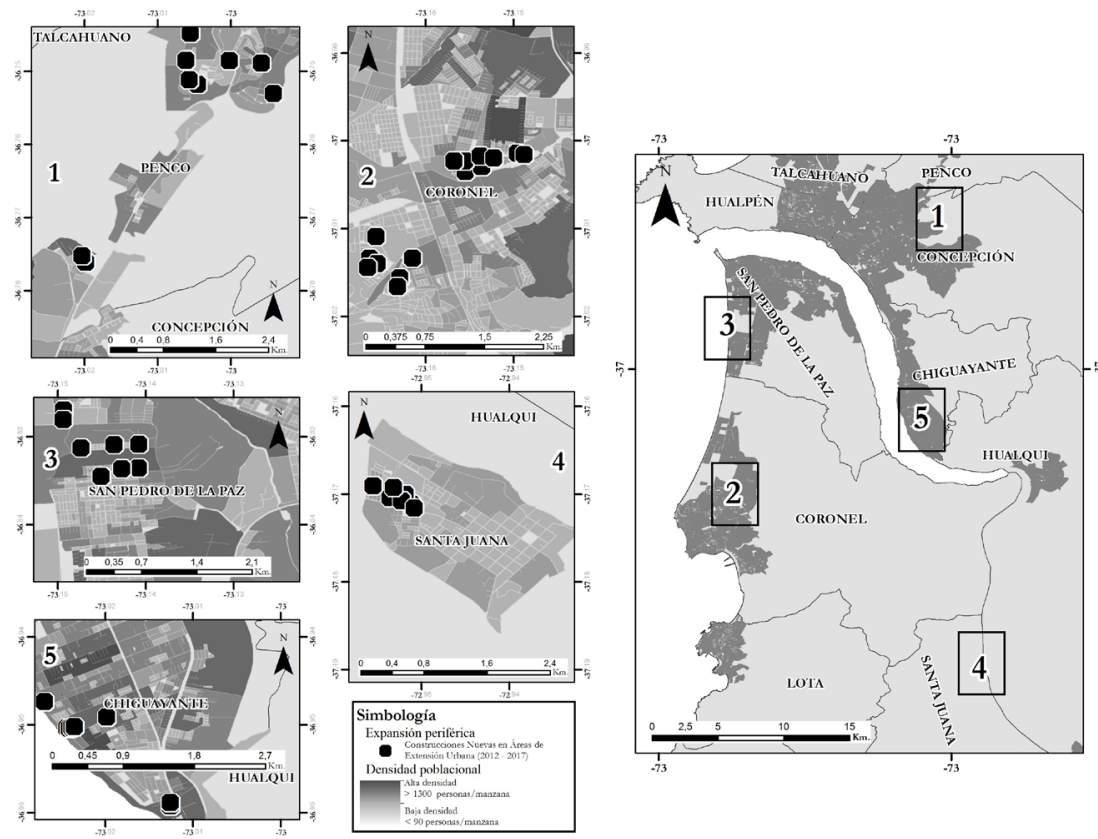

FUENTE: ELABORACIÓN PROPIA A PARTIR DE MINVU (20I9)

En consonancia con lo anterior, la aplicación de un análisis mediante autocorrelación espacial (Figura 5) manifiesta la presencia de áreas con mayor cantidad de permisos, con alto número de unidades cada una (que se refieren generalmente a promociones residenciales unifamiliares) alrededor de la Ruta 160. Dichas áreas se concentran en dos espacios señalados anteriormente y más próximos al centro: San Pedro de la Paz, junto a la costanera del Biobío, y Lomas de San Sebastián. Ambos se configuran como entornos de prestigio y cercanos a amenidades, en contraste con la zona Coronel-Lota, donde se estarían ubicando las promociones de vivienda social. De esta forma, se reafirma la tendencia a una fuerte segregación espacial del crecimiento inmobiliario, en este caso de baja densidad, al igual que sucede en otros casos de estudio (Janoschka \& Sequera, 2016; Michelini \& Pintos, 2016; Steel et al., 2017). Según tal tendencia, mientras las promociones de mayor prestigio 
ocuparían lugares más céntricos, agotando el suelo disponible, las promociones de vivienda social se desarrollarían en la periferia.

\section{FIgura 4 | Ubicación de Proyectos de Integración Social mediante Subsidios, DS 19 y Ds 116 (2016-2017)}
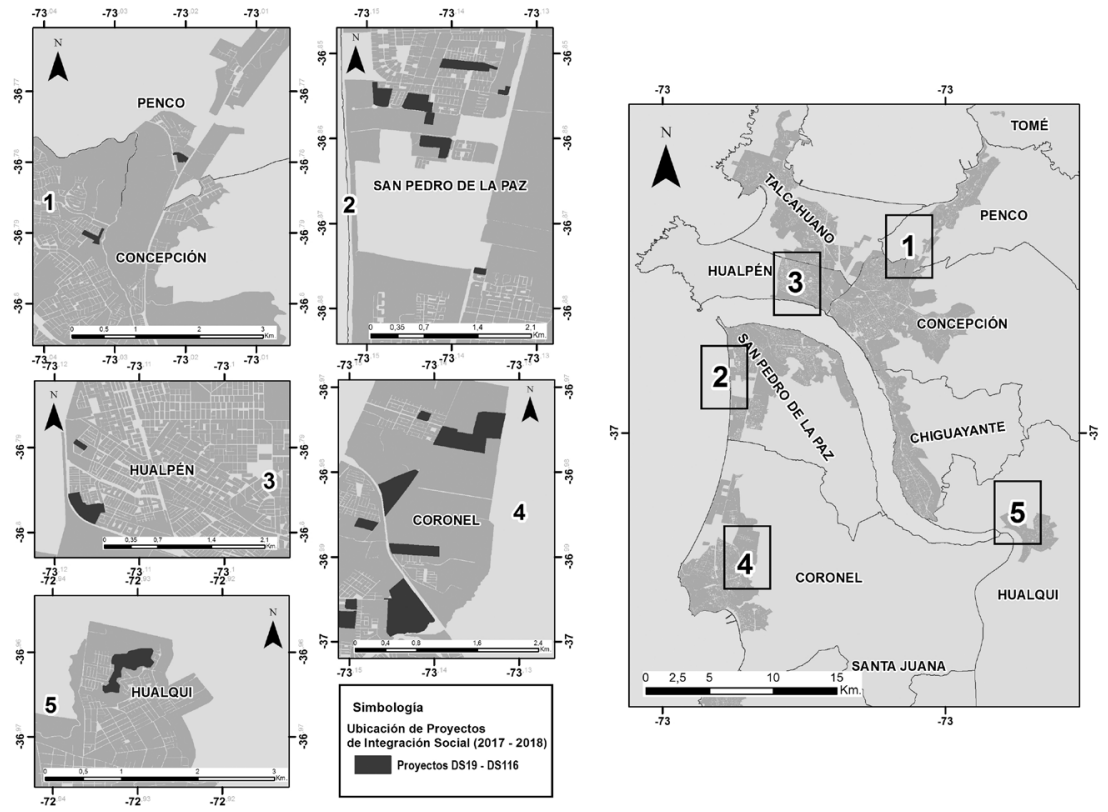

FUENTE: ELABORACIÓN PROPIA A PARTIR DE MINVU (2019)

A partir del análisis de las entrevistas, se infiere, de acuerdo con ACTi, que quienes son dueńos del suelo urbano, al elevar su precio en el mercado, conducen a una expansión urbana hacia la periferia, propiciada por un menor valor del suelo en aquellos sectores de expansión urbana: "[Los] tenedores del suelo urbano especulan con su precio; eso hace que en lugares periféricos el suelo sea más barato y, por lo tanto, explica también desarrollos en expansión [baja densidad]". Esta visión coincidiría con la perspectiva de Steel et al. (2017) respecto del papel estratégico del acaparamiento de suelo y la posibilidad de llevar a cabo grandes desarrollos en la periferia, mencionado en la revisión de la literatura. Un elemento clave en la decisión de invertir y desarrollar proyectos, que en este caso se asocia a la creación de lo que los entrevistados denominan "nuevos barrios" (con viviendas unifamiliares, áreas verdes y equipamientos), tiene que ver -como señala АCT14- con la presencia de infraestructura adecuada, vías rápidas o la futura posibilidad de su creación. Como indica АСт20: "Hasta mediados de la década del 2000 se hicieron desarrollos de vivienda social por trato directo, el Estado llegaba y construía. Después de 2010, se abandonó [esto] y llegó esta política de viviendas con subsidio (...). Originalmente, en torno a la Ruta 160 estaba pensado para ser construido sin subsidios, pero ocurrió 
una depreciación producto de la congestión vial que a principios de 2000 no existía (...) estos terrenos se depreciaron muchísimo, a tal punto que no queda otra solución que vivienda por subsidio".

\section{FIGURA 5 | Autocorrelación espacial de permisos de edificación (número de unidades) en AMC}

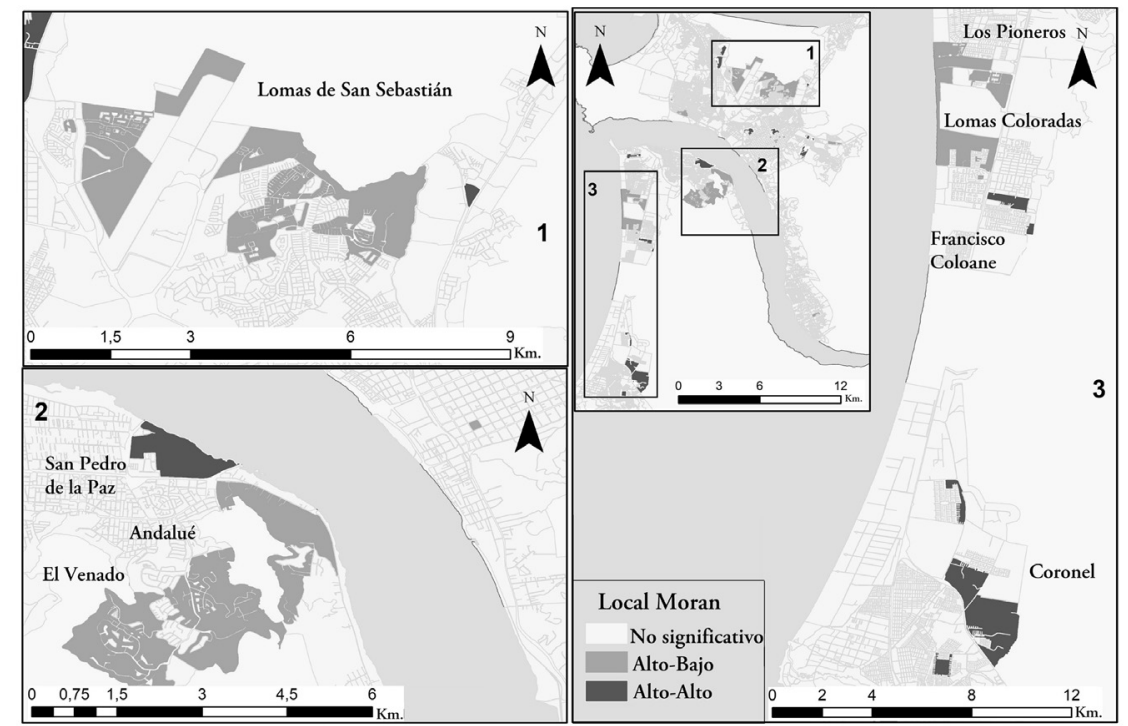

FUENTE: ELABORACIÓN PROPIA A PARTIR DE INE (2OI7)

En definitiva, lo que hizo el Estado fue poner en el mercado una vivienda que no era rentable, y lo hizo mediante una serie de subsidios que hicieron apetecibles estos terrenos a las empresas constructoras. Así, el crecimiento urbano está directamente vinculado a la propiedad de la tierra, los agentes intervinientes y la gestión del suelo, los cuales, en sus interrelaciones, configuran la expansión de la mancha urbana. Dicho panorama resultaría similar al que mostraba la literatura internacional, con un rol subsidiario del Estado y una vinculación entre intereses privados y políticas públicas (Storper, 2013). Esta expansión generaría en el AMC nuevas áreas urbanas consolidadas, incrementándose con ello el valor del suelo aún disponible. De acuerdo con ACT9, "[se agota el suelo en] Concepción en general (...). San Pedro ya está 'reventado' y no sé cuántos paños más hay. Hoy día, nosotros por un terreno tenemos a tres personas que lo quieren comprar".

Finalmente, АСт8 señala que "muchos de nuestros proyectos, vienen divididos en proyectos que son viviendas vulnerables, de los Ds 19 y Ds 116. Esto, ¿qué significa? Que las personas han puesto solamente su ahorro, el subsidio se lo ha cubierto completamente el gobierno, y estamos hablando de una vivienda que hoy día está llegando a las 1.100 uf. Entonces, la persona adquiere una vivienda y no paga nada, solamente el ahorro (...) y eso pasa con proyectos de departamentos y casas". En 
estos últimos comentarios aparecería tanto el rol "facilitador" del Estado, comentado en la revisión de la literatura a nivel nacional e internacional (Brites, 2017; Molina et al., 2019; van Lindert, 2016), como el papel de la vivienda subsidiada a la hora de propiciar una propietarización de las clases medias y bajas a través de un modelo que, si bien soluciona la tenencia de una vivienda, consolida la fragmentación y segregación socioespacial (Dammert et al., 2019; Hidalgo, Santana \& Link, 2018; López-Morales, 2015).

\section{Futuras áreas de crecimiento}

El futuro crecimiento del AMC parece asociado directamente al desarrollo inmobiliario privado de la ciudad. En la actualidad se mantendría una dinámica de "ciudad difusa", donde el crecimiento se organizaría en torno a las principales vías y la locomoción privada, siendo fundamental la presencia de ejes como la Ruta 160, la vía a Penco, o la "Ruta de la Madera" hacia Santa Juana, junto con la red ferroviaria del Biotrén. Estos serían elementos determinantes en el futuro desarrollo periférico de la ciudad. De acuerdo con DemoData (2018), el ascenso de la población de San Pedro en lo que a estrato socioeconómico se refiere consolida esta comuna como una suerte de extensión de Concepción, haciendo más compleja la conurbación tradicional Concepción-Talcahuano (Salinas \& Pérez, 2011). Esto es clave para comprender cómo los procesos urbanos van modificando el AMC, con el desarrollo simultáneo en San Pedro de una concentración de proyectos de integración social junto con otros de prestigio, cuyo resultado es la existencia de altos niveles de segregación territorial, visibles en las diferencias entre sectores como Andalué o El Venado (alto estándar) y Candelaria o Bocasur (vivienda social). Los edificios, en tanto, no se concentrarían solo en las áreas centrales, donde parece que continuará el proceso de renovación urbana vinculado a la demanda estudiantil; también se proyectan en las periferias de la ciudad, en las zonas de expansión aún disponibles, como los espacios donde hay predisposición a proyectos de integración social con alturas intermedias (5-8 pisos). Igualmente, como pudo apreciarse en la Figura 2, la zona de la costanera refleja dicha dualidad mediante edificios en altura de importante plusvalía en el mercado.

En este sentido, la Figura 6 presenta el área de posible expansión urbana, cuyo análisis espacial se construye sobre los PRC de las 13 comunas del Área Metropolitana. En dichos planes reguladores comunales solo se consideraron las áreas de extensión urbana de carácter habitacional; es decir, se filtraron áreas verdes, de protección, zonas de patrimonio y de riesgo, quedando solamente el suelo apto para expansión habitacional. A ello se le superpuso el área urbana consolidada, ya que sobre esta solo se pueden producir procesos de verticalización o renovación urbana, por lo que la expansión urbana como tal no podría desarrollarse. Finalmente, se georreferenciaron los Estudios de Impacto Ambiental (EIA) ingresados al Sistema de Evaluación de Impacto Ambiental previos a la obtención de permisos para el desarrollo de proyectos inmobiliarios. Esto último está directamente relacionado con las intenciones de expansión urbana de las empresas inmobiliarias, la proyección de crecimiento urbano hacia sectores clave y su intención al adquirir pańos en los 
límites del área urbana, a la espera de que cambie el uso de suelo que les está asignado y sean declarados aptos para la urbanización, lo que supone una oportunidad de negocio. En su mayor parte, los resultados se localizan en las comunas de Santa Juana y Hualqui, las de menor urbanización en el AMC y con mayor disponibilidad de suelo, lo que habría sido mencionado por algunos entrevistados, como ACT7: "Se optó por nuevos proyectos (...) en Hualqui, donde a nadie le interesaba construir; nosotros fuimos y obtuvimos un reconocimiento de las personas, con viviendas de muy buena calidad. Por eso el boom que ha tenido".

FIgURA 6 | Proyección de la futura expansión urbana del AMC

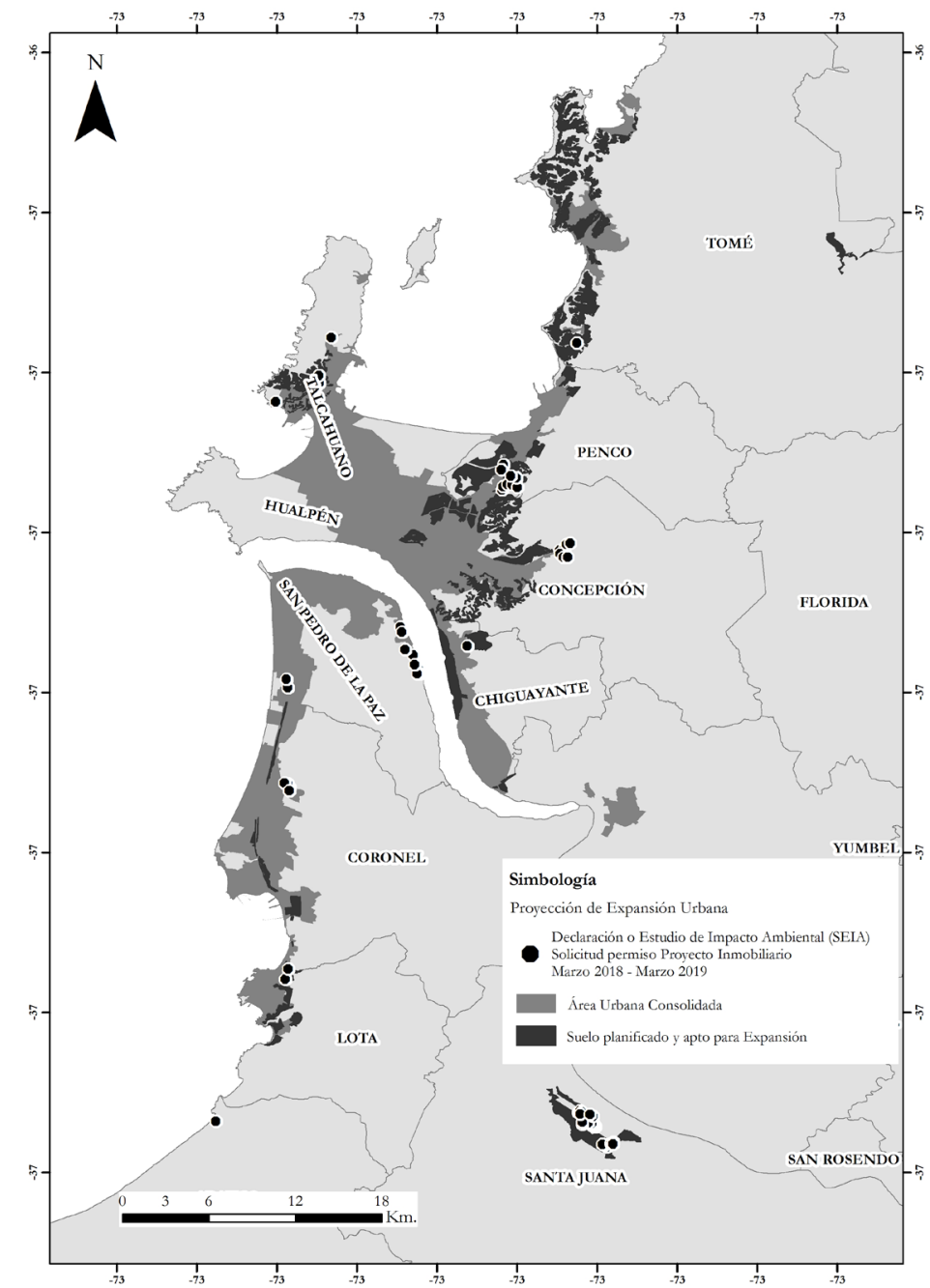

FUENTE: ELABORACIÓN PROPIA A PARTIR DE MINVU (20I9) y SERVICIO DE EVALUACión AMBIENTAL (SEA, 20I9) 
Dados los antecedentes mencionados, pueden apreciarse solicitudes de EIA para proyectos inmobiliarios fuera del área urbana consolidada en las comunas San Pedro de la Paz y Concepción, cuyo valor del suelo es el más elevado del Amc. Sin embargo, la mayoría de solicitudes, y con ello el interés de las empresas inmobiliarias en grandes proyectos, se localiza fuera del área urbana consolidada, en espacios que no eran hasta entonces "urbanizables" dada la mala calidad del suelo, problemas de conectividad, falta de red de agua y electricidad o nulos servicios, por lo que la planificación territorial no los ha considerado como sectores de proyección de expansión urbana, ni aptos para su urbanización. En San Pedro destaca el sector Camino a Santa Juana, donde se ha establecido un nicho de urbanizaciones cerradas y un nuevo polo de barrios exclusivos.

Así, para las empresas inmobiliarias, la idea de expansión urbana se asocia al crecimiento en zonas más rurales, con un discurso que promueve la sustentabilidad y la creación de nuevos sectores diferenciados del área urbana actual. Sin embargo, tales sectores requieren ser urbanizados para el desarrollo de sus proyectos. Un ejemplo de ello es el proyecto de la empresa Valmar en Chaimávida, donde se prevé construir 853 casas y 1.300 departamentos en un terreno de 70 hectáreas (Diario Concepción, 2018). En contraste con esto, desde la municipalidad se ha planteado que la zona tiene baja aptitud para el desarrollo urbano, dada la mala calidad del suelo y la ausencia de equipamientos y servicios. Sin embargo, para uno de los entrevistados (ACT7), "[en] Concepción viene crecimiento para el sector de Chaimávida. Yo creo que 'después' del río Andalién estamos hablando de 100 o 200 hectáreas que quedan disponibles para la construcción. No está delimitado en Concepción para dónde va a crecer". Esta disociación entre sector público y privado es reflejada por АСт19 cuando indica: "Están en caminos absolutamente separados, el sector privado construye donde le sea más rentable y los instrumentos son tan débiles que no están en condiciones de impedir que el privado se termine instalando". Chaimávida es ejemplo de la que ha sido habitualmente la estrategia de crecimiento urbano, basada en la concentración y posterior venta de suelo por parte de las empresas inmobiliarias, o el desarrollo de proyectos urbanos propios de gran envergadura, unido al uso de las subvenciones gubernamentales como ancla en la venta de productos inmobiliarios. Es esto lo que finalmente genera un crecimiento urbano vulnerable, asociado a la segregación urbana, la falta de servicios y la deficiente movilidad urbana, como ha ocurrido en el pasado en las urbanizaciones en la Ruta 160. Por lo mismo, a futuro el rol del sector público continuará siendo meramente subsidiario, en un contexto donde los agentes privados tienen la iniciativa para planificar el crecimiento urbano.

\section{Discusión y conclusiones}

Como ha podido observarse, el caso de estudio del AMC coincide con la literatura internacional en que el principal factor que dinamiza el crecimiento y morfología urbana del espacio metropolitano es el precio del suelo, con las inmobiliarias como principal agente encargado de "crear ciudad" (Harvey, 2001; Inzulza-Contardo, 2016). De esta forma, el modelo de negocio ha consistido hasta ahora en comprar 
grandes extensiones de suelo en las futuras zonas de expansión urbana o en los espacios aledaños, adelantándose a los procesos de urbanización realizados posteriormente por los gobiernos comunales. Ante al aumento del precio del suelo, los propietarios venden sus terrenos o se encargan de generar y gestionar barrios ex novo, lo que está al alcance solo de las inmobiliarias. La altísima rentabilidad que se produce supone nuevo combustible para la maquinaria de expansión urbana que se menciona en la literatura especializada (De Mattos et al., 2016; Rolnik, 2013), debido a que la vivienda se consolida como bien en el cual invertir con miras al arriendo o la venta futura. En paralelo a este crecimiento urbano, el centro, a pesar de su progresiva pérdida de población, sufriría un intenso proceso de renovación urbana traducido en la verticalización del mismo, impulsada por el alto costo del suelo y con el objetivo de sacar el mayor provecho de su localización y acceso a servicios. Esta dinámica arrojaría similitudes con el modelo de ciudad com-fusa (Abramo, 2012), presente en otras urbes latinoamericanas; y, en menor medida, con el concepto de ciudad mestiza, puesto que permanece una superposición de lo presente y lo pretérito en la concreción espacial (Ciccolella, 2016) que, en este caso, se visualizaría en la acelerada renovación sobre barrios consolidados. Por lo tanto, el crecimiento metropolitano del Gran Concepción no diferiría, al menos en lo morfológico, de otras dinámicas urbanas regionales (Fuentes \& Pezoa, 2017; Janoschka, 2003; Michelini \& Pintos, 2016). Sin embargo, junto a esos procesos generales, es posible encontrar singularidades locales explicables por el carácter universitario del AMC, el importante peso de la vivienda social y los atractivos paisajísticos. Los mismos constituyen procesos y mecanismos distintivos, que permiten avanzar en la comprensión de las dinámicas urbanas en ciudades secundarias.

En primer lugar, el hecho de que Concepción atraiga a más de 100.000 estudiantes en su área metropolitana genera un nicho de mercado que ha espoleado la construcción de edificios de departamentos, y ello no en los espacios más centrales o con mejores servicios, sino alrededor de los principales campus universitarios, dando lugar a una verticalización selectiva del AMC. Este crecimiento sería financiado por el boom en las hipotecas a la vivienda, relacionado no solo con el "valor seguro" que para gran parte de la población supone la vivienda, sino también con las incertidumbres del modelo de pensiones chileno, ya que la inversión inmobiliaria sería un seguro para la vejez, entroncando así con la economía política de la vivienda (Aalbers \& Christophers, 2014). Sería interesante comparar si otras ciudades secundarias cuentan con procesos y mecanismos similares que expliquen dinámicas paralelas (por ejemplo, La Serena y los arriendos turísticos; o Antofagasta y los arriendos a trabajadores de la minería).

En segundo lugar, la conjunción de ayudas estatales a la reconstrucción tras el terremoto de 2010 y de subsidios para la vivienda y los arriendos, dieron un fuerte impulso a la expansión urbana que ya se venía desarrollando. Así, con los Ds 19 y Ds 116 comienza la construcción de proyectos de integración social, siendo los créditos públicos los impulsores de los mismos los que ponen en el mercado paños de vivienda que, sin el subsidio, no serían rentables, propietarizando nuevos sectores de la población (Hidalgo et al., 2017). De esta forma, el rol subsidiario de lo público aparece aquí, pero como un actor sin capacidad de decisión, y solamente replicando 
políticas ideadas en otras escalas y con el sismo de 2010 como hito que explicaría parte del intenso crecimiento en la década de 2010.

En tercer lugar, la existencia de valores paisajísticos, asociados a los humedales y a la costanera del Biobío, ha dado lugar a varios proyectos de prestigio en espacios que no siempre resultan accesibles o adecuados a la construcción, por tratarse de zonas de relleno. Este valor natural ha asegurado, sin embargo, la presencia de clientes-objetivo para estos productos y ha cimentado una notoria segregación socioespacial, que tiene su contrapartida en la expulsión de la vivienda social hacia la periferia. Este fenómeno sería especialmente visible en San Pedro, donde en la actualidad se puede apreciar un incremento del número de edificios en áreas concretas, asociadas a productos de alto nivel económico. Este hecho supone una continuación en la línea que abrieron Hidalgo, Rodríguez \& Alvarado (2018) sobre ciudades "fluviales", ampliándose en este caso las inversiones desde la vivienda social hasta las actuaciones de prestigio.

A futuro, es esperable que la consolidación de la tendencia a aprovechar la ciudad como producto para generar beneficios mediante el sistema de hipotecasendeudamiento-arriendo, que en el caso de estudio viene espoleado por la presencia de estudiantes, mantenga el proceso de crecimiento vertical. Esto, que comienza a ser criticado por parte de algunos sectores sociales que ven cómo, en paralelo, los barrios se vacían de habitantes (expulsados por el alto precio del suelo) y se llenan de edificios para estudiantes, alineará los procesos ocurridos en el centro de Concepción con los de otras ciudades chilenas (Santiago) o latinoamericanas (Buenos Aires). En ellas, las dinámicas de expulsión de los habitantes del centro resultan, por el tamaño de estas urbes, más visibles, pero guardan una lógica común de mercantilización de los espacios urbanos, la misma que se señalaba en la revisión de la literatura.

Finalmente, este trabajo abre un campo de estudios en relación con la posibilidad de analizar e interpretar otros casos de ciudades secundarias latinoamericanas, buscando dinámicas generales y especificidades que puedan explicar los ámbitos comunes y propios de los actuales procesos inmobiliarios en estos espacios.

\section{Agradecimientos}

Este trabajo se realizó en el marco del Proyecto Fondecyt de Iniciación no 11170019 "Estrategias locales de desarrollo integral en las ciudades del sur de Chile ¡crecimiento, vulnerabilidad, crisis y resiliencia?"

\section{Referencias bibliográficas}

Aalbers, M. (2016). The financialization of housing. A political economy approach. Routledge. Aalbers, M. \& Christophers, B. (2014). Centering housing in political economy. Housing, Theory and Society, 31(4), 373-394. https://dx.doi.org/10.1080/14036096.2014.947082 
Abramo, P. (2012). La ciudad com-fusa: mercado y producción de la estructura urbana en las grandes metrópolis latinoamericanas. Revista EURE - Revista de Estudios Urbano Regionales, 38(114), 35-69. https://dx.doi.org/10.4067/S0250-71612012000200002

Anselin, L. (1995). Local Indicators of Spatial Association - LISA. Geographical Analysis, 27(2), 93-115. https://doi.org/10.1111/j.1538-4632.1995.tb00338.x

Arenas, A. \& Mesa, C. (2006). The structural pension reform in Chile: effects, comparisons with other Latin American reforms, and lessons. Oxford Review of Economic Policy, 22(1), 149-167. https://doi.org/10.1093/oxrep/grj010

Borsdorf, A. \& Hidalgo, R. (2007). New dimensions of social exclusion in Latin America: from gated communities to gated cities, the case of Santiago de Chile. Land Use Policy, 25(2), 153-160. https://dx.doi.org/10.1016/j.landusepol.2007.04.001

Brites, W. F. (2017). La ciudad en la encrucijada neoliberal. Urbanismo mercado-céntrico y desigualdad socioespacial en América Latina. Urbe. Revista Brasileira de Gestão Urbana, 9(3), 573-586. https://doi.org/10.1590/2175-3369.009.003.ao14

Cámara Chilena de la Construcción (cchc). (2017). La evolución del mercado inmobiliario en el Gran Concepción. Concepción Construye, 101. http://concepcionconstruye.cl/ ediciones 2017

Cámara Chilena de la Construcción (cchc). (2018). Venta de viviendas nuevas en el Gran Concepción. Concepción Construye, 107. http://concepcionconstruye.cl/ ediciones-2018

Cares, D., Bustamante, G. \& Poblete, D. (2017). Propuesta de indicador de costos en la construcción y efecto que tienen nuevas normativas para edificaciones en altura del Gran Concepción. Simposio de habilitación profesional. Departamento de Ingeniería Civil, Universidad Católica de la Santísima Concepción. http://repositoriodigital.ucsc. cl/bitstream/handle/25022009/1421/Cares\%20Sep\%c3\%balveda\%2c\%20Diego. pdf?sequence $=1$ \&isAllowed $=y$

Cattaneo, R. (2011). Los fondos de inversión inmobiliaria y la producción privada de vivienda en Santiago de Chile: ¿Un nuevo paso hacia la financiarización de la ciudad? Revista EURE - Revista de Estudios Urbano Regionales, 37(112), 5-22. https://dx.doi. org/10.4067/S0250-71612011000300001

Christophers, B. (2011). Revisiting the urbanization of capital. Annals of the Association of American Geographers, 101(6), 1347-1364. http://dx.doi.org/10.1080/00045608.20 11.583569

Ciccolella, P. (2016). Mestizaje territorial en las metrópolis latinoamericanas en el contexto de la crisis actual del capitalismo. En S. Silva (Ed.), Transformaçöes metropolitanas no século xxi: Bahia, Brasil e América Latina (pp. 27-48). Editora da Universidade Federal da Bahia (EDUfBA).

Daher, A. (2013). Territorios de la financiarización urbana y de las crisis inmobiliarias. Revista de Geografia Norte Grande, 56, 7-30. https://dx.doi.org/10.4067/S071834022013000300002

Dammert, M., Delgadillo, V. \& Erazo, J. (2019). Bibliografía sobre América Latina: nuevas desigualdades urbanas. Andamios, 16(39), 255-262. http://dx.doi.org/10.29092/ uacm.v16i39.682 
De Mattos, C. (2016). Financiarización, valorización inmobiliaria del capital y mercantilización de la metamorfosis urbana. Sociologias, 18(42), 24-52. https://dx.doi. org/10.1590/15174522-018004202

De Mattos, C., Fuentes, L. \& Link, F. (2016). Mutations in the Latin American metropolis Santiago de Chile under neoliberal dynamics. En O. Nel.lo \& R. Mele (Eds.), Cities in the 21st Century (pp. 80-92). Routledge.

DemoData (2018). Transformación del Área Metropolitana de Concepción: nuevas formas de ocupar el territorio. Universidad de Concepción. http://demodata.cl/wp-content/ uploads/2018/08/Transformaci\%C3\%B3n-del-\%C3\%81 rea-Metropolitana-deConcepci\%C3\%B3n.pdf

Diario Concepción (2018, octubre 9). Valmar invertirá US\$350 millones en proyecto en sector Chaimávida. https:/www.diarioconcepcion.cl/economia-y-negocios/2018/10/09/ valmar-invertira-us350-millones-en-inedito-proyecto-en-sector-chaimavida.html

Diario Concepción (2019, enero 15). San Pedro de la Paz aparece en el top 10 de ciudades que más crece en densificación en altura del país. https://www.diarioconcepcion.cl/ ciudad/2019/01/15/san-pedro-de-la-paz-aparece-en-el-top-10-de-ciudades-que-mascrece-en-densificacion-en-altura-del-pais.html

Fedele, J. \& Martínez, I. (2015). Verticalización y desarrollo inmobiliario del núcleo urbano central de Santa Fe: cambios morfológicos, conflictos urbanos y regulaciones edilicias en la recuperación poscrisis 2001. Cuaderno Urbano. Espacio, Cultura, Sociedad, 18(18), 65-88. http://dx.doi.org/10.30972/crn.1818265

Forcael, E., Andalaft, A., Schovelin, R. \& Vargas, P. (2013). Aplicación del método de opciones reales en la valoración de proyectos inmobiliarios. Obras y proyectos, (14), 58-70. https://dx.doi.org/10.4067/S0718-28132013000200005

Fuentes, L., Link, F. \& Valenzuela, F. (2017). Impactos de la dinámica urbana en los mercados laborales en las principales ciudades chilenas. Cadernos Metrópole, 19(38), 157-177. https://dx.doi.org/10.1590/2236-9996.2017-3806

Fuentes, L. \& Pezoa, M. (2017). Crecimiento urbano reciente del Gran Valparaíso. ¿¿Hacia una reconfiguración com-fusa? Revista 180, (40), 108-118. http://dx.doi.org/10.32995/ rev180.Num-40.(2017).art-328

Fuster-Farfán, X. (2019). Las políticas de vivienda social en Chile en un contexto de neoliberalismo híbrido. Revista EURE - Revista De Estudios Urbano Regionales, 45(35), 5-26. https://dx.doi.org/10.4067/S0250-71612019000200005

Harvey, D. (2001). Spaces of capital. Towards a critical geography. Routledge.

Hidalgo, R. (1999). La vivienda social en Chile: La acción del Estado en un siglo de planes y programas. Scripta Nova, 45(1). http://www.ub.edu/geocrit/sn-45-1.htm

Hidalgo, R., Alvarado, V., Quijada, P. \& Santana, D. (2017). Estado y propiedad: la política de vivienda social y la construcción de rutas hacia el neoliberalismo en América Latina y Chile. Revista de Ciencias Sociales, 9(32), 11-33. http://ridaa.unq.edu.ar/ handle/20.500.11807/1686

Hidalgo, R., Rodríguez, L. \& Alvarado, V. (2018). Arriba del cerro o sobre el humedal: producción de naturaleza y expansión inmobiliaria en ciudades marinas y fluviales. El caso de Valparaíso y Valdivia, Chile. Diálogo Andino, (56), 87-100. http://dx.doi. org/10.4067/S0719-26812018000200087 
Hidalgo, R., Santana, L. \& Link, F. (2018). New neoliberal public housing policies: between centrality discourse and peripheralization practices in Santiago, Chile. Housing Studies, 34(3), 489-518. https://dx.doi.org/10.1080/02673037.2018.1458287

Instituto Nacional de Estadísticas (INE), Chile. (2017). Permisos de Edificación principales ciudades, Microdatos Manzanas Censales. http://geoine-ine-chile.opendata.arcgis.com/

Instituto Nacional de Estadísticas (INE), Chile. (2018). Anuario de edificación comunal Año 2017 Región del Biobio. Sintesis de resultados. http://www.inebiobio.cl/archivos/files/ pdf/estadisticas_economicas/edificacion/ANUARIO\%20Estadistico\%20Sintesis\%20 2017.pdf

Inzulza-Contardo, J. (2016). Contemporary Latin American gentrification? Young urban professionals discovering historic neighbourhoods. Urban Geography, 37(8), 11951214. https://dx.doi.org/10.1080/02723638.2016.1147754

Janoschka, M. (2003) Nordelta-ciudad cerrada. El análisis de un nuevo estilo de vida en el Gran Buenos Aires. Scripta Nova, 7(146). https://doi.org/10.1344/sn2003.7.760

Janoschka, M. \& Sequera, J. (2016). Gentrification in Latin America: addressing the politics and geographies of displacement. Urban Geography, 37(8), 1175-1194. http://dx.doi. org/10.1080/02723638.2015.1103995

Lefebvre, H. (1970). La revolution urbaine. Gallimard.

Lencioni, S. (2014). Reestruturação imobiliária: uma análise dos processos de concentração e centralização do capital no setor imobiliário. Revista EURE - Revista de Estudios Urbano Regionales, 40(120), 29-47. http://dx.doi.org/10.4067/S0250-71612014000200002

Lois, R., Piñeira, M. \& Vives, S. (2016). The urban bubble process in Spain: An interpretation from the theory of the circuits of capital. Journal of Urban and Regional Analysis, 8(1), 5-20. http://hdl.handle.net/10347/22761

López-Morales, E. (2015). Gentrification in the global South. City, 19(4), 564-573. https:// dx.doi.org/10.1080/13604813.2015.1051746

López-Morales, E. (2016). A multidimensional approach to urban entrepreneurialism, financialization, and gentrification in the high-rise residential market of inner Santiago, Chile. Risking Capitalism (Research in Political Economy, vol. 31, 79105). Emerald Group Publishing Limited. https://dx.doi.org/10.1108/S0161723020160000031005

Lukas, M. \& López-Morales, E. (2017). Real estate production, geographies of mobility and spatial contestation: A two-case study in Santiago de Chile. Journal of Transport Geography, 67, 92-101. http://dx.doi.org/10.1016/j.jtrangeo.2017.09.005

Méndez, R. (2018). La telaraña financiera. Una geografía de la financiarización y su crisis. Colección Estudios Urbanos Uc, RIL Editores.

Michelini, J. \& Pintos, P. (2016). Metropolitan expansion and new socio-spatial segregation scenarios in contemporary Argentina. The case of Nordelta-Las Tunas. Habitat International, 54, 40-49. https://doi.org/10.1016/j.habitatint.2015.08.011

Ministerio de Vivienda y Urbanismo (mINvu), Chile. (2011). Iniciativas de densificación urbana. Cartilla $N^{\circ} 1$. Programa Fondo Solidario de Elección de Vivienda. Santiago. http://www.minvu.cl/incjs/download.aspx?glb_cod_nodo=20160707130207\&hdd_ nom_archivo=CARTILLA_N_1_Iniciativas_de_densificaci\%C3\%B3n.pdf 
Ministerio de Vivienda y Urbanismo (mINvu), Chile. (2019). Construcciones nuevas (20122017), Ubicación de Proyectos de Integración Social (2017-2018), Área Urbana Consolidada y Zonificación prc. http://www.ide.cl/index.php/informacion-territorial/ descargar-informacion-territorial

Molina, I., Czischke, D. \& Rolnik, R. (2019). Housing policy issues in contemporary South America: an introduction. International Journal of Housing Policy, 19(3), 277-287. https://doi.org/10.1080/19491247.2019.1627843

Napadensky, A. \& Orellana, A. (2019). Metropolización y organización funcional de sistemas urbanos intermedios. Bitácora Urbano/Territorial, 29(1), 65-78. https://dx.doi. org/10.15446/bitacora.v29n1.67325.

Pérez, L., González, G., Villouta, D., Pagola, L. \& Ávila, C. (2019). Procesos de reestructuración y verticalización en el centro de Concepción: Barrio Condell. Revista de Urbanismo, (41), 1-17. https://dx.doi.org/10.5354/0717-5051.2019.53926

Prada-Trigo, J. (2019a). Crecimiento inmobiliario y desarrollo urbano en Concepción. Factores y manifestaciones de las desigualdades intraurbanas. Presentado en xi Seminario Internacional de Investigación en Urbanismo (siiu), 2-6 de septiembre, Santiago de Chile. No publicado.

Prada-Trigo, J. (2019b). Understanding studentification dynamics in low-income neighbourhoods: Students as gentrifiers in Concepción (Chile). Urban Studies, 56(14), 2863-2879. https://doi.org/10.1177/0042098018807623

Rolnik, R. (2013). Late neoliberalism: The financialization of homeownership and housing rights. International Journal of Urban and Regional Research, 37(3), 1058-1066. https:// doi.org/10.1111/1468-2427.12062

Salinas, E. \& Pérez, L. (2011). Procesos urbanos recientes en el Área Metropolitana de Concepción: transformaciones morfológicas y tipologías de ocupación. Revista de Geografia Norte Grande, (49), 79-97. http://dx.doi.org/10.4067/S071834022011000200006

Schovelin, R. (2004). Modelo de maximización de ingresos de proyectos inmobiliarios de departamentos, mediante selección de características en el Gran Concepción, Chile. Theoria, 13(1), 25-36. https://www.redalyc.org/pdf/299/29901303.pdf

Servicio de Evaluación Ambiental (sEA), Chile. (2019). Solicitud de Permisos para Proyecto Inmobiliario (Marzo 2018 - Marzo 2019) Región del Biobio. https://seia.sea.gob.cl/ busqueda/buscarProyecto.php

Steel, G., van Noorloos, F. \& Klaufus, C. (2017). The urban land debate in the global South: New avenues for research. Geoforum, 83, 133-141. https://doi.org/10.1016/j. geoforum.2017.03.006

Storper, M. (2013). Keys to the city: how economics, institutions, social interaction, and politics shape development. Princeton University Press.

van Lindert, P. (2016). Rethinking urban development in Latin America: A review of changing paradigms and policies. Habitat International, 54, 253-264. https://doi.org/10.1016/j. habitatint.2015.11.017

Vergara-Arribas, N. (2020). Real estate and the production of urban space: a pervasive debt of Latin American(ist) geography. Journal of Latin American Geography, 19(1), 204-214. https://dx.doi.org/10.1353/lag.2020.0013 